\title{
Vaginal cuff brachytherapy: do we need to treat to more than a two-centimeter active length?
}

\author{
Garrett L. Jensen, MD', Parul N. Barry, MD2,3, Harriet Eldredge-Hindy, MD², Scott R. Silva, MD², Sarah L. Todd, MD4, \\ Kendall P. Hammonds, MPH', Walker R. Zimmerman, BS', Daniel S. Metzinger, MD4, Moataz N. El-Ghamry, MD1,2 \\ 'Department of Radiation Oncology, Baylor Scott and White Health, Temple, USA, ${ }^{2}$ Department of Radiation Oncology, Division \\ of Gynecologic Oncology, University of Louisville School of Medicine, James Graham Brown Cancer Center, Lovisville, USA, ${ }^{3}$ Department \\ of Radiation Oncology, UPMC Hillman Cancer Center, Magee Women's Hospital, Pittsburgh, USA, “Department of Obstetrics and Gynecology. \\ Division of Gynecologic Oncology, University of Lovisville School of Medicine, James Graham Brown Cancer Center, Lovisville, USA, \\ ${ }^{5}$ Department of Biostatistics, Baylor Scott and White Health, Temple, USA
}

\begin{abstract}
Purpose: American Brachytherapy Society (ABS) guidelines recommend using a 3-5 $\mathrm{cm}$ active length (AL) when treating vaginal cuff (VC) in adjuvant setting of endometrial cancer (EC). The purpose of this study was to evaluate local control and toxicity, using an AL of 1 or $2 \mathrm{~cm}$ and immobilization with a traditional table-mounted (stand) or patient-mounted (suspenders) device.

Material and methods: Between 2005 and 2019, 247 patients with EC were treated with adjuvant high-dose-rate vaginal cuff (HDR-VC) brachytherapy with or without external beam radiation (EBRT). Treatment was prescribed to a $0.5 \mathrm{~cm}$ depth, with an AL of 1 or $2 \mathrm{~cm}$, using stand or suspenders. VC boost after EBRT was typically administered with 2 fractions of $5.5 \mathrm{~Gy}$, while VC brachytherapy alone was typically applied with 3 fractions of 7 Gy or 5 fractions of $5.5 \mathrm{~Gy}$.

Results: The combination of suspender immobilization and an AL of $2 \mathrm{~cm}(n=126,51 \%)$ resulted in 5-year local control of $100 \%$. An AL of $2 \mathrm{~cm}$ compared to $1 \mathrm{~cm}$ correlated with better local control $(99.1 \%$ vs. 88.5\%, $p=0.0479)$. Regarding immobilization, suspenders correlated with improved local control compared to stand (100\% vs. $86.7 \%$, $p=0.0038)$. Immobilization technique was significantly correlated with AL $(p<0.0001)$. Only $5(2.0 \%)$ patients experienced grade $\geq 3$ toxicity, all of whom received EBRT.

Conclusions: In the present series, an AL of $2 \mathrm{~cm}$ provided excellent local control, while $1 \mathrm{~cm}$ was inadequate. Suspender immobilization was a practical alternative to stand immobilization in HDR brachytherapy of the vaginal cuff.

J Contemp Brachytherapy 2021; 13, 3: 294-301 DOI: https://doi.org/10.5114/jcb.2021.105971
\end{abstract}

Key words: vaginal cuff, brachytherapy, immobilization, active length, endometrial.

\section{Purpose}

Endometrial cancer is the most common gynecologic malignancy in the United States, with an estimated 65,620 new cases in 2020 [1]. Many women diagnosed at an early stage have excellent survival with surgery alone. A significant risk of recurrent disease remains for women with stage I disease and high-intermediate risk features, stage II disease [2], or in more advanced stages. Vaginal cuff is the most common site of post-operative failure, and vaginal cuff brachytherapy (VCB) has become an integral part of adjuvant therapy, either with or without external beam radiotherapy (EBRT) to the pelvis, to obviate the risk of vaginal cuff recurrence in appropriately selected patients [3-7].

There is a marked lack of consensus regarding vaginal cuff treatment parameters [7-10]. This has resulted in innumerable acceptable treatment options by the Ameri- can Brachytherapy Society (ABS) [11, 12]. ABS guidelines recommend treating with an active length (AL) of 3-5 cm $\mathrm{VCB}$, following hysterectomy [11]. Practices vary broadly, but the most common fixed and fractional length prescriptions in endometrial cancer are $4 \mathrm{~cm}$ or the proximal half of the vagina, respectively [8]. Wide practice variances are often due to a lack of data. However, length of vaginal irradiation as well as volume have been known to be associated with vaginal shortening and stenosis for decades [13-16]. Less described in the literature is a relationship between the length of vagina irradiation and vaginal recurrence $[14,17]$. The common prescription depth of $5 \mathrm{~mm}$, though potentially more toxic than prescribing to the surface, can be justified by location of vaginal lymphatics $[8,18,19]$. Without similar evidence, and in the absence of residual disease, common VBT prescription lengths may be excessive.
Address for correspondence: Moataz N. El-Ghamry, MD, Department of Radiation Oncology, Baylor Scott and White Health, 2401 S 31 ${ }^{\text {st }}$ St., MS-09-C011, Temple, TX 76508, USA, phone: +1-254-724-0836, fax: +1-254-724-8061, e-mail: Moataz.ElGhamry@BSWHealth.org
Received: 21.11 .2020

Accepted: 09.03 .2021

Published: 07.05.2021 
Vaginal cuff movement can be significant from bladder and rectum volume variation $[20,21]$. The vaginal cylinder itself can also cause displacement and altered dose distribution depending on how it is positioned [22]. Traditional table-mounted immobilization (i.e., stand) of the vaginal cylinder is susceptible to inter- and intra-fraction changes in patient positioning. Custommounted patient immobilization devices (e.g., suspenders), may better control for these inter- and intrafraction changes.

The aim of the present study was to evaluate the efficacy, in terms of local control and toxicity, of using a 1 or $2 \mathrm{~cm} \mathrm{AL}$ in the treatment of endometrial cancer with VCB. Similarly, we evaluated the impact of immobilization technique (table- vs. patient-mounted) within the same population.

\section{Material and methods}

After obtaining institutional review board approval (IRB 017-227), 247 patients were retrospectively identified in the electronic medical record of two institutions who met all study criteria. Included patients were diagnosed with endometrial cancer and treated with adjuvant highdose-rate (HDR) brachytherapy to the vaginal cuff, following hysterectomy with or without EBRT to the vagina and pelvis between January 2005 and November 2019. Tables 1 and 2 present patients' and treatments' characteristics, respectively. Patients were excluded if they had gross residual disease in the vagina or endometrial sarcoma. Treatment of the study population was delivered via vaginal cylinder prescribed to a $0.5 \mathrm{~cm}$ depth, with an AL of $1 \mathrm{~cm}$ in 118 (47.7\%) patients and $2 \mathrm{~cm}$ in 129 (52.2\%) patients. Only 7 patients were identified who were treated with an AL of greater than $2 \mathrm{~cm}$, and these patients were excluded from the analysis due to paucity of representation. Immobilization during brachytherapy was with a stand in $109(44.1 \%)$ patients and suspenders in 138 (55.9\%) patients. Suspender immobilization uses an in-house adapter attached to the vaginal cylinder central channel, with two strips of twill tape threaded into the adaptor and tied over the shoulders of the patient (Figure 1).

Table 1. Patient characteristics

\begin{tabular}{|c|c|c|c|c|}
\hline \multirow[t]{3}{*}{ Variable } & \multicolumn{3}{|c|}{ Active length prescription } & \multirow[t]{3}{*}{$P$-value } \\
\hline & All, $n(\%)$ & $1 \mathrm{~cm}, n(\%)$ & $2 \mathrm{~cm}, n(\%)$ & \\
\hline & $247(100)$ & $118(47.8)$ & $129(52.2)$ & \\
\hline Immobilization & & & & $<0.0001$ \\
\hline Stand & $109(44.1)$ & $106(90.0)$ & $3(2.3)$ & \\
\hline Suspenders & $138(55.9)$ & $12(10.2)$ & $126(97.7)$ & \\
\hline Surgery type & & & & $<0.0001$ \\
\hline $\mathrm{TAH} / \mathrm{BSO}$ & $57(52.3)$ & $16(13.6)$ & $41(31.8)$ & \\
\hline TAH/BSO/PLN & $49(20.3)$ & $8(6.8)$ & $41(31.8)$ & \\
\hline TAH/BSO/PLN/PaLN & $117(48.4)$ & $81(68.6)$ & $36(27.9)$ & \\
\hline Other & $19(7.9)$ & $10(8.5)$ & $9(7.0)$ & \\
\hline Stage & & & & 0.01 \\
\hline $\mathrm{IA}$ & $94(38.2)$ & $56(47.5)$ & $38(29.5)$ & \\
\hline IB & $73(29.7)$ & $32(27.1)$ & $41(31.8)$ & \\
\hline II & $17(6.9)$ & $3(2.5)$ & $14(10.9)$ & \\
\hline III & $58(23.6)$ & $25(21.2)$ & $33(25.6)$ & \\
\hline IV & $4(1.6)$ & $2(1.7)$ & $2(1.6)$ & \\
\hline Pathology & & & & 0.0081 \\
\hline Adenocarcinoma & $178(72.1)$ & $91(77.1)$ & $87(67.4)$ & \\
\hline Papillary serous/clear cell & 45 (18.2) & $23(19.5)$ & $22(17.1)$ & \\
\hline Adenosquamous & $18(7.3)$ & $4(3.4)$ & $14(10.9)$ & \\
\hline Other & $6(2.4)$ & $0(0.0)$ & $6(4.7)$ & \\
\hline Grade & & & & 0.9683 \\
\hline 1 & $33(14.7)$ & $12(10.2)$ & $21(16.3)$ & \\
\hline 2 & $82(36.6)$ & $42(35.6)$ & $40(31.0)$ & \\
\hline 3 & $109(48.6)$ & $48(40.7)$ & $61(47.3)$ & \\
\hline Follow-up time, median (range) & 36 months (3-144) & 46.5 months (3-113) & 28 months (3-144) & \\
\hline
\end{tabular}

TAH - total abdominal hysterectomy, BSO - bilateral salpingo-oophorectomy, PLN - pelvic lymph node dissection, Plan - paraaortic lymph node dissection 
Table 2. Radiation treatment characteristics

\begin{tabular}{|c|c|c|c|}
\hline Variable & $1 \mathrm{~cm}$ active length & $2 \mathrm{~cm}$ active length & $P$-value \\
\hline $\begin{array}{l}\text { Most common treatment regimens to } \mathrm{VC} \\
\text { only }\left(\mathrm{BED}_{2}\right)\end{array}$ & $\begin{array}{l}5.5 \mathrm{~Gy} \times 5\left(n=37,35.5 \mathrm{~Gy}_{2}\right) \\
5.5 \mathrm{~Gy} \times 4\left(n=16,28.4 \mathrm{~Gy}_{2}\right)\end{array}$ & $\begin{array}{l}7 \mathrm{~Gy} \times 3\left(n=39,29.8 \mathrm{~Gy}_{2}\right) \\
5.5 \mathrm{~Gy} \times 4\left(n=7,28.4 \mathrm{~Gy}_{2}\right)\end{array}$ & N.A. \\
\hline $\begin{array}{l}\text { Most common boost treatment regimen } \\
\text { with EBRT }\left(\mathrm{BED}_{2}\right)\end{array}$ & $\begin{array}{c}5.5 \text { Gy } \times 2 \text { following } 50.4(n=27) \\
\text { or } 45.0 \mathrm{~Gy}(n=22) \\
\text { of EBRT }\left(58.5-63.8 \mathrm{~Gy}_{2}\right)\end{array}$ & $\begin{array}{c}5.5 \text { Gy } \times 2 \text { following } 50.4(n=31) \\
\text { or } 45.0 \text { Gy }(n=12) \\
\text { of EBRT }\left(58.5-63.8 \mathrm{~Gy}_{2}\right)\end{array}$ & N.A. \\
\hline VC dose per fraction & 550 cGy (400-708.3) & 550 cGy (400-700) & $<0.0001$ \\
\hline VC total dose & 2050 cGy (400-4250) & 1100 cGy $(550-3500)$ & $<0.0001$ \\
\hline VC number of fractions & $3(1-6)$ & $2(1-5)$ & $<0.0001$ \\
\hline \multicolumn{4}{|l|}{ EBRT } \\
\hline Yes & $57(23.1)$ & $50(20.2)$ & \multirow[t]{2}{*}{0.0412} \\
\hline No & $61(24.7)$ & 79 (32.0) & \\
\hline EBRT dose, median (range) & 5040 cGy (4500-5040) & 5040 cGy (4500-5625) & 0.0159 \\
\hline Total VC BED 2 , median (range) & 4899 cGy (933-7756) & 5846 cGy (992-8344) & 0.3254 \\
\hline
\end{tabular}

$V C$ - vaginal cuff, EBRT - external beam radiotherapy, BED 2 - biologic equivalent dose at 2 Gy, N.A. - not applied
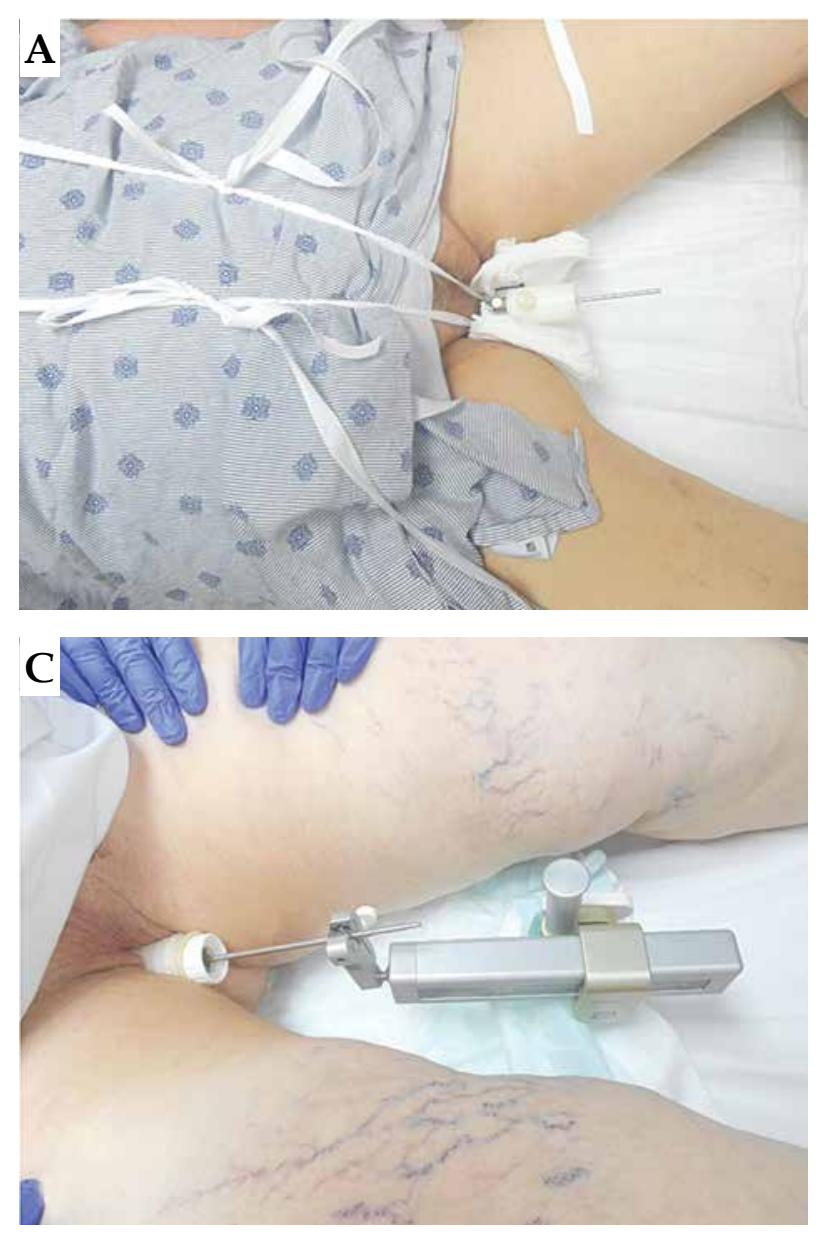

Prior to treatment planning, fiducial markers were placed at the vaginal cuff, usually at 3 and 9 o'clock. Treatment planning was either 2D- or 3D-based, without clinical target volume (CTV) delineation. For 179 pa-

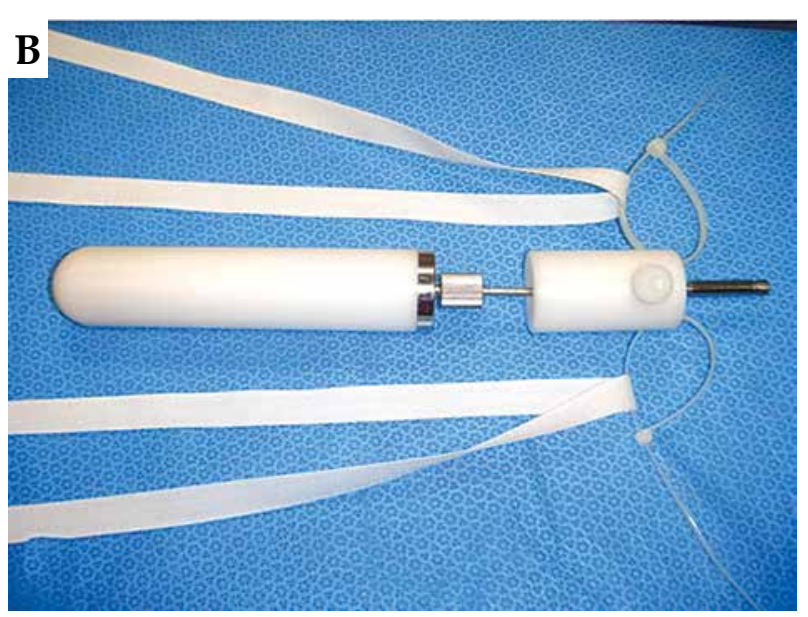

Fig. 1. Immobilization by A) suspenders with B) custom in-house device, or with C) stand

tients, 2D atlas-based library plans were used with fluoroscopy. For 68 patients, 3D planning was used with a computed tomography (CT) scan performed prior to each fraction to ensure correct placement and diameter 
of the cylinder. A remote afterloader tested for channel obstruction and dwell times were independently checked. Daily QA included verification of the source position and interlocks. At the time of source exchange, after calibration, verification of the source positioning was performed. All vaginal cylinders were examined annually for physical integrity, with scans used to check for center channel damage and to verify offsets used in the treatment planning system. Cylinder diameter was chosen based on patient anatomy. Treatment plans were optimized using treatment planning software to ensure $100 \%$ isodose line coverage at $5 \mathrm{~mm}$ depth. On extremely rare occasions, isodose lines were manually modified to avoid the bladder or rectum.

After completion of radiation, the patients were followed every 3 months during the first 2 years and then, every 6 months up to 5 years or more. Median follow-up time was 36 months (range, 3-144 months). They were evaluated for recurrence and side effects by clinical and gynecological examinations as well as imaging studies. The patients were not censored for vaginal recurrence at the time of distant or nodal recurrence and continued to receive monitoring.

Toxicity was assessed using common terminology criteria for adverse events v. 5.0 guidelines. The highest grade of vaginal toxicity during treatment or on follow-up with a radiation oncologist or gynecologic oncologist was recorded. For all women, vaginal dilators were provided but compliance was infrequently reported and thus precluded from toxicity analysis.

Chi-square, Fisher's exact, or Wilcoxon rank-sum tests were used to compare characteristics of the 1 and $2 \mathrm{~cm}$ AL populations. Bivariate analysis was used to assess overall survival by AL and vaginal recurrence as well as vaginal recurrence by $\mathrm{AL}$ and immobilization method. Chi-square or Fisher's exact tests were used to test for an association between AL and toxicity. Low number of events precluded multivariate analysis. SAS version 9.4 (SAS Institute Inc., Cary, NC, USA) was used for statistical analysis.

\section{A}

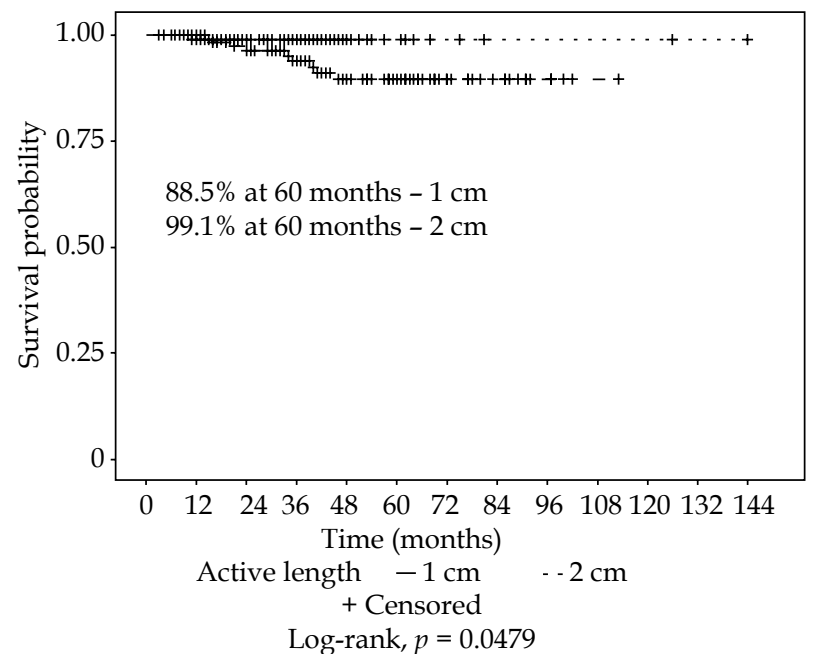

\section{Results}

The patients' and treatments' characteristics are presented in Tables 1 and 2. The patients received different fractionation schedules in terms of total dose and number of fractions, all of which were converted to a biologically effective dose (BED) ${ }_{2}$ at $0.5 \mathrm{~cm}$ depth using the $\mathrm{L} / \mathrm{Q}$ model (Table 2). Those who received EBRT, typically obtained 4500 or 5040 cGy with subsequent brachytherapy to two fractions of 550 cGy (58.5-63.8 $\mathrm{Gy}_{2}$ total), while patients who did not, typically received 3 fractions of 700 cGy or 5 fractions of 550 cGy (35.5 or $29.8 \mathrm{~Gy}_{2}$, respectively). Patients treated with an AL of $2 \mathrm{~cm}$ were significantly more likely to be immobilized with suspenders than a stand (97.7\% vs. $2.3 \%, p<0.0001)$.

For all the patients, the overall survival (OS) rates at 2 and 5 years was $95.5 \%$ and $77.0 \%$, respectively. An OS difference was not detected by AL $(p=0.8050)$. Patients with a vaginal recurrence had a 5 -year OS of $61.7 \%$ vs. $77.7 \%$ for those without ( $p=0.2654$ ).

For all the patients, the vaginal recurrence rates at 2 and 5 years were $1.9 \%$ and $8.0 \%$, respectively. Overall recurrence rates at 2 and 5 years were $11.9 \%$ and $20.3 \%$, respectively. Patients treated with an AL of $1 \mathrm{~cm}$ had a significantly worse 5-year vaginal recurrence free survival (VRFS) than those with an AL of $2 \mathrm{~cm}(88.5 \%$ vs. $99.1 \%$, $p=0.0479)$. Patients treated with suspender immobilization had a higher 5-year VRFS (100.0\% vs. $86.7 \%$, $p=0.0038)$. The most common combination of $2 \mathrm{~cm} \mathrm{AL}$ with suspenders $(n=126,51 \%)$ had a $100 \%$ local control at 5 years (Figure 2). Immobilization technique was significantly correlated with AL $(p<0.0001)$. Patients treated with or without EBRT did not have a significantly different VRFS (94.3\% vs. $91.5 \%, p=0.4354)$. Low number of events prevented log-rank analysis by EBRT and AL (Figure 3).

Table 3 shows patients' toxicities. Grades 1-2 vaginal toxicity were experienced in $21.7 \%$ and $14.6 \%$ of patients with and without EBRT, respectively. No grade 3 or 4 vaginal toxicities were documented. Grades 1-3 rectal toxicity were experienced in $63.4 \%$ and $8.2 \%$ of patients with and without EBRT, respectively. Grades 1-3 bladder

B

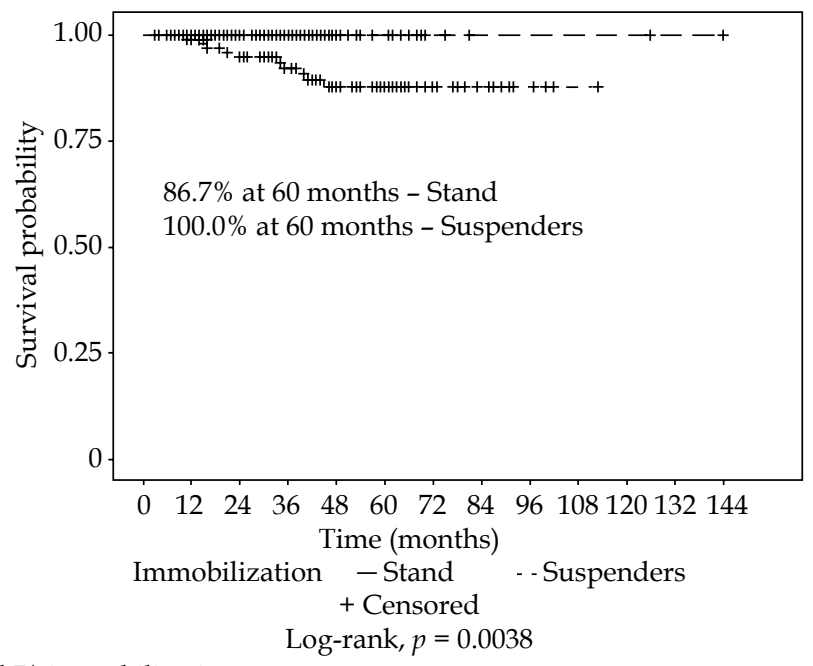

Fig. 2. Freedom from vaginal recurrence by $\mathbf{A}$ ) active length and $\mathbf{B}$ ) immobilization 
A

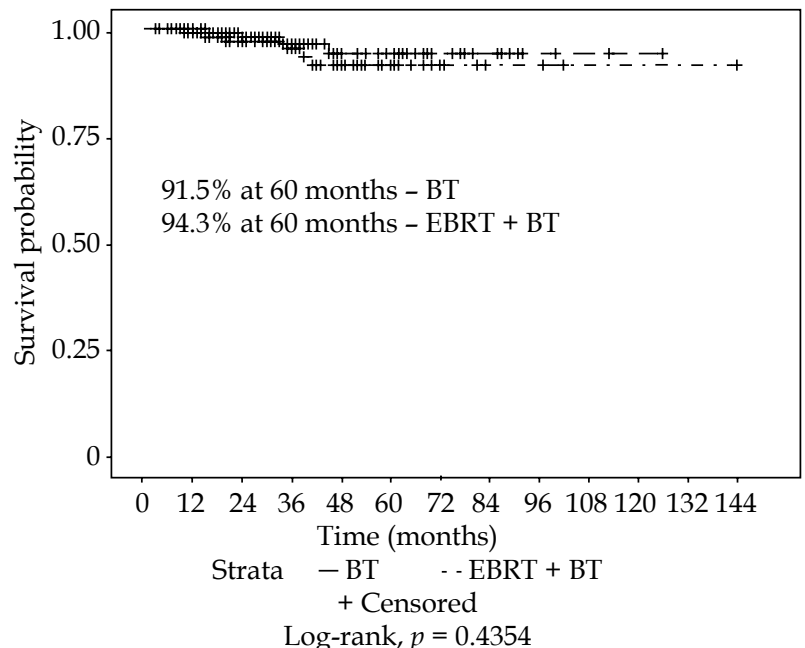

B

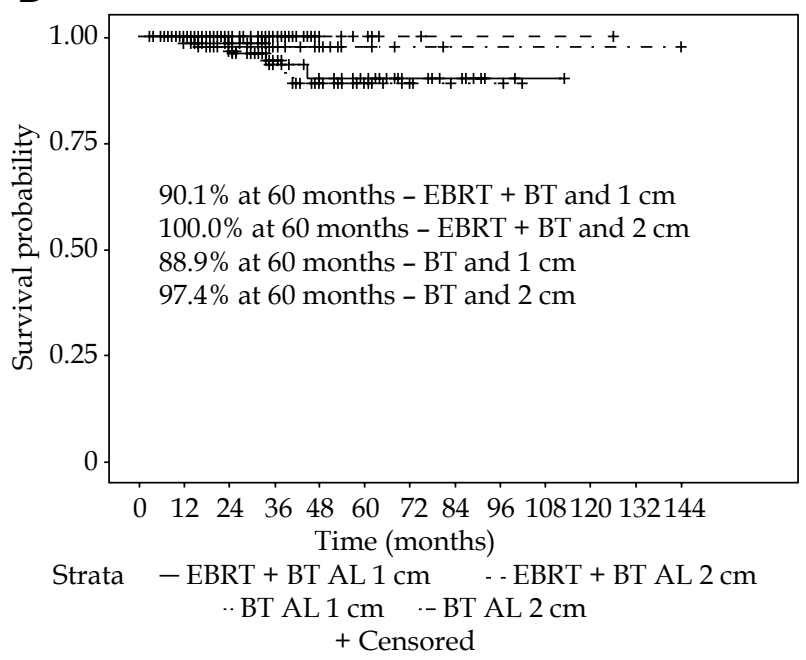

Fig. 3. Freedom from vaginal recurrence by A) brachytherapy with or without external beam radiotherapy for all patients, or by $\mathbf{B})$ active length

Table 3. Toxicity

\begin{tabular}{|c|c|c|c|c|c|c|c|c|c|c|c|}
\hline \multirow[t]{2}{*}{ Type } & \multirow[t]{2}{*}{ Grade } & \multicolumn{3}{|c|}{ Patients, $n(\%)$} & \multirow[t]{2}{*}{$P$-value ${ }^{1}$} & \multicolumn{2}{|c|}{ With EBRT, $n(\%)$} & \multirow[t]{2}{*}{$P$-value ${ }^{2}$} & \multicolumn{2}{|c|}{ Without EBRT, $n(\%)$} & \multirow[t]{2}{*}{$P$-value ${ }^{1}$} \\
\hline & & Total & $\begin{array}{l}\text { With } \\
\text { EBRT }\end{array}$ & $\begin{array}{c}\text { Without } \\
\text { EBRT }\end{array}$ & & $1 \mathrm{~cm} \mathrm{AL}$ & $2 \mathrm{~cm} \mathrm{AL}$ & & $1 \mathrm{~cm} \mathrm{AL}$ & $2 \mathrm{~cm} \mathrm{AL}$ & \\
\hline \multirow[t]{3}{*}{ Vaginal } & None & $198(81.5)$ & $105(43.2)$ & $93(38.3)$ & \multirow[t]{3}{*}{0.1646} & $48(35.8)$ & $57(42.5)$ & \multirow[t]{3}{*}{0.0798} & $55(50.5)$ & 38 (34.9) & \multirow[t]{3}{*}{0.0383} \\
\hline & 1 & $35(14.4)$ & \multirow[t]{2}{*}{29 (11.9) } & \multirow[t]{2}{*}{$16(6.6)$} & & \multirow[t]{2}{*}{$8(6.0)$} & \multirow[t]{2}{*}{21 (15.7) } & & \multirow[t]{2}{*}{$5(4.6)$} & \multirow[t]{2}{*}{11 (10.1) } & \\
\hline & 2 & $10(4.1)$ & & & & & & & & & \\
\hline \multirow[t]{4}{*}{ Rectal } & None & 149 (61.3) & $49(20.2)$ & $100(41.2)$ & \multirow[t]{4}{*}{$<0.0001$} & $22(16.4)$ & $27(20.2)$ & \multirow[t]{4}{*}{0.5798} & $55(50.5)$ & $45(41.3)$ & \multirow[t]{4}{*}{1.0000} \\
\hline & 1 & $43(17.7)$ & \multirow[t]{3}{*}{85 (35.0) } & \multirow[t]{3}{*}{$9(3.7)$} & & \multirow[t]{3}{*}{$34(25.4)$} & \multirow[t]{3}{*}{$51(38.1)$} & & \multirow[t]{3}{*}{$5(4.6)$} & \multirow[t]{3}{*}{$4(3.7)$} & \\
\hline & 2 & $47(19.3)$ & & & & & & & & & \\
\hline & 3 & $4(1.7)$ & & & & & & & & & \\
\hline \multirow[t]{4}{*}{ Bladder } & None & $183(75.3)$ & $86(35.4)$ & 97 (39.9) & \multirow[t]{4}{*}{$<0.0001$} & 38 (28.4) & $48(35.8)$ & \multirow[t]{4}{*}{0.4518} & $50(45.9)$ & $47(43.1)$ & \multirow[t]{4}{*}{0.0368} \\
\hline & 1 & $43(17.7)$ & \multirow[t]{3}{*}{48 (19.8) } & \multirow[t]{3}{*}{$12(4.9)$} & & \multirow[t]{3}{*}{18 (13.4) } & \multirow[t]{3}{*}{$30(22.4)$} & & \multirow[t]{3}{*}{$10(9.2)$} & $2(1.8)$ & \\
\hline & 2 & $16(6.6)$ & & & & & & & & & \\
\hline & 3 & $1(0.4)$ & & & & & & & & & \\
\hline
\end{tabular}

${ }^{1}$ With EBRT vs. without EBRT, any grade toxicity, ${ }^{2} 1 \mathrm{~cm}$ vs. $2 \mathrm{~cm}$, any grade toxicity, EBRT - external beam radiotherapy, AL-active length prescription

toxicity were experienced in $35.8 \%$ and $11.0 \%$ of patients with and without EBRT, respectively.

\section{Discussion}

Post-operative irradiation decreases locoregional relapses in high/intermediate-risk endometrial cancer, and vaginal cuff brachytherapy achieves vaginal control similar to EBRT with lower toxicity [3, 4]. Even though not demonstrated in randomized trials, the National Cancer Database and the Surveillance, Epidemiology, and End Results Database have shown evidence for improved survival in intermediate- and high-risk groups [23-25]. Following the PORTEC-2 demonstrating equivalent local control of vaginal cylinder to EBRT in early-stage patients with decreased toxicity [3], it makes sense to find the least toxic way to administer vaginal radiation without sacrificing local control. This is especially true without a well-established survival benefit.
In patients treated with an $\mathrm{AL}$ of $2 \mathrm{~cm}$ with suspenders, no patient developed a recurrence of the vaginal cuff. Seldom described is the effect of vaginal irradiation length on vaginal recurrence and survival. Kloetzer et al. observed no difference in survival or vaginal recurrence treating only proximal half of the vagina [17]. Surprisingly, one analysis found that overall recurrence was correlated with increased prescription length, though this was not discussed in the paper, and it was most likely due to differences in disease [14]. We found a significant difference in vaginal cuff recurrence between patients treated with an AL of 1 and $2 \mathrm{~cm}$ (5-year recurrence rates of $11.5 \%$ and $0.9 \%$, respectively). There were many significant differences between the 1 and $2 \mathrm{~cm}$ populations, but most of those differences strengthen this finding. Patients treated with an AL of $2 \mathrm{~cm}$ had significantly higher stages, less extensive nodal dissections, less EBRT at lower doses, and lower total brachytherapy dose. A difference that weakens our finding was the decreased amount of 
Table 4. Vaginal recurrence in the literature Vaginal recurrence following adjuvant vaginal cuff brachytherapy

\begin{tabular}{|c|c|c|c|c|c|c|c|c|c|}
\hline Authors & $\begin{array}{l}\mathrm{AL}(\mathrm{cm} \text { or } \\
\text { vaginal } \\
\text { fraction) }\end{array}$ & Year & $\begin{array}{l}\text { Patients } \\
\text { (n) }\end{array}$ & $\begin{array}{l}\text { FIGO } \\
\text { stage }\end{array}$ & $\begin{array}{c}\text { EBRT } \\
(\%)\end{array}$ & $\begin{array}{l}\text { Brachytherapy treat- } \\
\text { ment (dose } \times \text { fractions) }\end{array}$ & $\begin{array}{l}\text { Depth } \\
(\mathrm{cm})\end{array}$ & $\begin{array}{l}\text { Median FU } \\
\text { (months) }\end{array}$ & $\begin{array}{l}\text { Vaginal } \\
\text { recur- } \\
\text { rence (\%) }\end{array}$ \\
\hline \multirow[t]{2}{*}{ Current study } & $2^{1}$ & 2020 & 126 & IA-IV & 61.2 & $\begin{array}{c}\text { Median } 7 \text { Gy } \times 3 \\
\text { or } 5.5 \mathrm{~Gy} \times 2(\mathrm{w} / \mathrm{EBRT})^{3} \\
\end{array}$ & 0.5 & 28.0 & 0.0 \\
\hline & 1 & 2020 & 118 & IA-IV & 48.3 & $\begin{array}{l}\text { Median } 5.5 \text { Gy } \times 5 \\
\text { or } \times 2(w / E B R T)^{4}\end{array}$ & 0.5 & 47.0 & 7.6 \\
\hline Hou et al. $[26]^{2}$ & Proximal 1/2 & 2019 & 390 & $\begin{array}{l}\text { stage I } \\
\text { (IR-HR) }\end{array}$ & 37.2 & $\begin{array}{c}5 \text { Gy } \times 5-6 \\
\text { or 4-6 Gy } \times 2-3(w / E B R T)\end{array}$ & 0.5 & 48.0 & 1.0 \\
\hline $\begin{array}{l}\text { Zhang et al. } \\
\text { [27] }\end{array}$ & 2.5 & 2019 & 325 & IA-IVB & 100.0 & $\begin{array}{c}4-6 \text { Gy } \times 3,5-6 \text { Gy } \times 2 \text {, } \\
\text { or } 7 \text { Gy } \times 1\end{array}$ & 0.5 & $51.0-95.0$ & 1.8 \\
\hline $\begin{array}{l}\text { Rovirosa et al. } \\
{[28]}\end{array}$ & 2.5 & 2017 & 146 & $|A-| \mid(\mid R)$ & 0.0 & $\begin{array}{c}4-6 \text { Gy } \times 6,4-5 \text { Gy } \times 4, \\
\text { or } 6 \text { Gy } \times 3\end{array}$ & 0.5 & $41.0-88.0$ & 0.0 \\
\hline $\begin{array}{l}\text { Sorbe et al. } \\
\text { [29] }\end{array}$ & $\begin{array}{l}\text { Proximal } \\
2 / 3\end{array}$ & 2012 & 527 & IA-IC (IR) & 50.0 & $\begin{array}{c}3 \text { Gy } \times 6,5.9 \text { Gy } \times 3 \text {, } \\
\text { or } 20 \text { Gy (LDR) }\end{array}$ & 0.5 & 62.0 & 3.3 \\
\hline $\begin{array}{l}\text { Diavolitsis } \\
\text { et al. [30] }\end{array}$ & $3-5$ & 2012 & 169 & IA & 0.0 & $\begin{array}{c}7 \text { Gy } \times 3,5.5 \text { Gy } \times 4 \text {, } \\
\text { or } 70 \text { Gy (LDR) }\end{array}$ & $\begin{array}{l}0.5 \text { or } \\
\text { ovoid } \\
\text { surface } \\
\text { (LDR) }\end{array}$ & 103.0 & 0.6 \\
\hline $\begin{array}{l}\text { Nout et al. } \\
\text { (PORTEC-2) [3] }\end{array}$ & 4.7 (mean) & 2010 & 213 & $\begin{array}{l}\text { IB-2A } \\
(H I R)\end{array}$ & 0.0 & 7 Gy $\times 3$ or 30 Gy (LDR) & 0.5 & 45.0 & 1.8 \\
\hline $\begin{array}{l}\text { Alektiar et al. } \\
\text { [31] }\end{array}$ & $\begin{array}{c}\text { Proximal } 1 / 2 \\
\text { to } 2 / 3 \\
(>\text { if } G 3)\end{array}$ & 2005 & 382 & $\mid \mathrm{B}-\mathrm{IIB}(\mathrm{IR})$ & 0.0 & $6-7 \mathrm{~Gy} \times 3$ & 0.5 & 48.0 & 1.8 \\
\hline $\begin{array}{l}\text { Horowitz et al. } \\
\text { [32] }\end{array}$ & 5 & 2002 & 164 & $\mid \mathrm{B}-\mathrm{IIB}(\mathrm{IR})$ & 0.0 & 7 Gy × 3 & 0.5 & 65.0 & 1.2 \\
\hline $\begin{array}{l}\text { Petereit et al. } \\
\text { [33] }\end{array}$ & $\begin{array}{l}\text { Not } \\
\text { reported }\end{array}$ & 1999 & 191 & $\begin{array}{l}\text { IA-C } \\
(\text { LR-IR) }\end{array}$ & 0.0 & 16.2 Gy × 2 & $\begin{array}{l}\text { Ovoid } \\
\text { surface }\end{array}$ & 38.0 & 0.0 \\
\hline $\begin{array}{l}\text { Eltabbakh } \\
\text { et al. [34] }\end{array}$ & $\begin{array}{l}\text { Not } \\
\text { reported }\end{array}$ & 1997 & 332 & I (LR) & 0.0 & 30 Gy (LDR) & 0.5 & 97.0 & 0.0 \\
\hline $\begin{array}{l}\text { Sorbe et al. } \\
\text { [13] }\end{array}$ & $\begin{array}{c}\text { Proximal } \\
2 / 3\end{array}$ & 1990 & 404 & $|A-| B$ & 0.0 & $4.5 \mathrm{~Gy} \times 6$ to $9 \mathrm{~Gy} \times 4$ & 1.0 & $\begin{array}{l}\text { Not report- } \\
\quad \text { ed }\end{array}$ & 0.7 \\
\hline
\end{tabular}

$A L$ - active length of prescription, EBRT-external beam radiotherapy, FU - follow-up, IR - intermediate-risk, HR - high-risk, LDR - low-dose-rate, $G$ - grade, ${ }^{1}$ with suspenders, ${ }^{2}$ with multi-channel applicators, ${ }^{3}$ range, $4-7$ Gy $\times 1-5,{ }^{4}$ range, 4-7 Gy $\times 1-6$

follow-up time in the patients treated with an $\mathrm{AL}$ of $2 \mathrm{~cm}$ compared to $1 \mathrm{~cm}$, which may have resulted in later recurrences not being captured. We were also unable to perform a multivariate analysis due to the low number of events. Table 4 demonstrates our recurrence rates in context of the literature [3, 13, 26-34]. Not all of these papers distinguished between a vaginal cuff specific recurrence and vaginal recurrence overall. In our patients, all recurrences had an epicenter within $2 \mathrm{~cm}$ of the vaginal apex, such that there was no difference. These papers also had varying proportions of patients who received EBRT, but receiving EBRT did not significantly impacted VRFS in our study.

The length of vagina irradiation is known to be associated with vaginal shortening and stenosis $[13,35]$. A recent analysis showed stenosis rates of $5 \%$ and $31 \%$, with prescription lengths of $2.5 \mathrm{~cm}$ and $5.0 \mathrm{~cm}$, respectively [14]. This same analysis found that stenosis rates correlated significantly with prescription depth (4\% vs. $21 \%$ at the surface and $5 \mathrm{~mm}$, respectively), but not with cylinder diameter, which, unlike prescription point and length, physicians tend to alter based on individual anatomy. Agnes et al. retrospectively analyzed 100 patients with endometrial cancer who received exclusive VBT post-operatively, with a median follow-up of 24 months, and found a correlation between an $\mathrm{AL} \geq 5 \mathrm{~cm}$ and increased vaginal toxicity $(p=0.002)$ in patients who had received VBT without EBRT. In the shortest AL series published, Zhang et al. observed that vaginal shortening was $>1 / 3$ in $9.7 \%$ of patients treated with an AL of $2.5 \mathrm{~cm}$. Late grade $2 \mathrm{vag}-$ inal toxicity in post-operative endometrial carcinoma was associated with a 68 Gy dose equivalent to 2 Gy per fraction $(\alpha / \beta=3 \mathrm{~Gy})$ at $2 \mathrm{~cm}^{3}$ of the vagina in patients who received EBRT and intracavitary radiation $[16,27]$.

Vaginal toxicity itself, particularly with regard to sexual function, is not well reported or standardized. Compliance with vaginal dilators, which in some studies has been shown to decrease vaginal atrophy $[15,36,37]$, is 
often not recorded, and this remained true in our retrospective analysis. A Cochrane review found insufficient reliable evidence for routine vaginal dilator use, but still recommended it in patients not sexually active [38]. Vaginal length changes can be reliably measured but alterations in sexual function are more difficult to quantify $[39,40]$. Zhang et al. assessed late toxicity of the rectum and bladder using Radiation Therapy Oncology Group (RTOG) scores, while late vaginal toxicity was evaluated with the objective criteria of LENT-SOMA [41, 42]. Here, we assessed toxicity using CTCAE 5.0 guidelines. Since no clear correlation of time from treatment to development of vaginal stenosis has been found in the literature $[15,35]$, we recorded the highest grade of vaginal toxicity during the treatment or at any available follow-up with a radiation or gynecologic oncologist. We found a higher rate of both bladder and vaginal toxicity (any grade) in patients treated with an AL of $1 \mathrm{~cm}$. This finding was unexpected and is most likely a result of provider and/or institutional bias, as all $1 \mathrm{~cm}$ patients were treated by several radiation oncology physicians, while a single physician treated a majority of $2 \mathrm{~cm}$ patients at multiple institutions. Additionally, the significantly shorter follow-up time of $2 \mathrm{~cm}$ patients (28 months) may have contributed to less late toxicity events being captured.

Unfortunately, similar institutional bias diminished the efficacy of analysis of toxicity or recurrence by immobilization type. We found a significant difference in vaginal cuff recurrence by stand vs. suspender immobilization technique (5-year recurrence rates of $13.3 \%$ and $0.0 \%$, respectively). However, there was a significant correlation between suspender immobilization and a $2 \mathrm{~cm}$ AL. Only 3 patients $(1.2 \%)$ were treated with a $2 \mathrm{~cm}$ AL using a stand, with 1 of them having a vaginal recurrence. Interestingly, this was the only vaginal recurrence in the patients treated with a $2 \mathrm{~cm}$ AL. Due to mild toxicity in patients who did not receive EBRT, any potential difference in side effects using suspenders would be difficult to detect.

Suspender immobilization was clinically beneficial in several instances. A number of patients moved during a treatment, usually because of pain or coughing, and thus had to be restimulated and planned. This was not the case with suspender immobilization, as the vaginal cylinder "moves" with the patient. At one institution, patients were typically treated in an HDR suite, following CT simulation in the same room. When the CT scanner was down for a repair, patients were able to receive their simulation in a separate room and then be transported for the treatment with the vaginal cylinder in place. Vaginal cylinders and stands can be marked in various ways, but external markings cannot always accurately replicate internal anatomical changes. The VC can move up to $34.5 \mathrm{~mm}$ during EBRT [20]. These are largely due to variations in the bladder and rectum volumes between fractions, but a cylinder can also cause different displacement of adjacent organs based on patient's and stand's positioning $[21,22]$. With suspender immobilization, the vaginal cylinder neutrally follows and stretches patient's vaginal canal, which minimizes air pockets and improves coverage at $0.5 \mathrm{~cm}$ depth, additionally allowing for adjustments that conform to motion of the vaginal canal.
Limitations of this study include its retrospective nature and a heterogeneous cohort, with regard to stage, dose, follow-up time, and surgery. Most significantly, patients treated with an AL of $2 \mathrm{~cm}$ had a significantly shorter follow-up time. There was a limited number of patients treated with an AL of $2 \mathrm{~cm}$ with a stand immobilization or an AL of $1 \mathrm{~cm}$ with suspender immobilization.

\section{Conclusions}

Excellent control of the vaginal cuff was obtained using patient-mounted suspender immobilization while treating to an AL of $2 \mathrm{~cm}$. Treating to an AL of $1 \mathrm{~cm}$ correlated with a significantly increased frequency of the vaginal cuff recurrence. The suspender immobilization offers several practical advantages and is a viable alternative to the stand immobilization in HDR brachytherapy of the vaginal cuff. Optimal brachytherapy with regards to dose, fractionation, and other treatment parameters remains ill-defined. More research, preferably with randomized phase III trials incorporating more objective and detailed monitoring of vaginal toxicity are needed.

\section{Disclosure}

Dr. Barry received an ACRO grant for a survey evaluating promotion of women in radiation oncology. Otherwise, none to disclose.

The authors report no conflict of interest.

\section{References}

1. Siegel RL, Miller KD, Jemal A. Cancer statistics, 2020. $C A$ Cancer J Clin 2020; 70: 7-30.

2. Rychlik A, Zapardiel I, Baquedano L et al. Clinical relevance of high-intermediate risk endometrial cancer according to European risk classification. Int J Gynecol Cancer 2020; 30: 1528-1534.

3. Nout R, Smit V, Putter H et al. Vaginal brachytherapy versus pelvic external beam radiotherapy for patients with endometrial cancer of high-intermediate risk (PORTEC-2): an open-label, non-inferiority, randomised trial. Lancet 2010; 375: 816-823.

4. Creutzberg CL, Nout RA, Lybeert MLM et al. Fifteen-year radiotherapy outcomes of the randomized PORTEC- 1 trial for endometrial carcinoma. Int J Radiat Oncol 2011; 81: e631-e638.

5. Nout RA, Putter H, Jürgenliemk-Schulz IM et al. Five-year quality of life of endometrial cancer patients treated in the randomised Post Operative Radiation Therapy in Endometrial Cancer (PORTEC-2) trial and comparison with norm data. Eur J Cancer 2012; 48: 1638-1648.

6. Keys HM, Roberts JA, Brunetto VL et al. A phase III trial of surgery with or without adjunctive external pelvic radiation therapy in intermediate risk endometrial adenocarcinoma: a Gynecologic Oncology Group study. Gynecol Oncol 2004; 92: 744-751.

7. Harkenrider MM, Block AM, Alektiar KM et al. American Brachytherapy Task Group Report: Adjuvant vaginal brachytherapy for early-stage endometrial cancer: A comprehensive review. Brachytherapy 2017; 16: 95-108.

8. Harkenrider MM, Grover S, Erickson BA et al. Vaginal brachytherapy for postoperative endometrial cancer: 2014 Survey of the American Brachytherapy Society. Brachytherapy 2016; 15: 23-29. 
9. Harkenrider MM, Block AM, Siddiqui ZA, Small W Jr. The role of vaginal cuff brachytherapy in endometrial cancer. Gynecol Oncol 2015; 136: 365-372.

10. Albuquerque K, Hrycushko BA, Harkenrider MM et al. Compendium of fractionation choices for gynecologic HDR brachytherapy - an American Brachytherapy Society Task Group Report. Brachytherapy 2019; 18: 429-436.

11. Small W Jr., Beriwal S, Demanes DJ et al. American Brachytherapy Society consensus guidelines for adjuvant vaginal cuff brachytherapy after hysterectomy. Brachytherapy 2012; 11: 58-67.

12. Nag S, Erickson B, Thomadsen B et al. The American Brachytherapy Society recommendations for high-dose-rate brachytherapy for carcinoma of the cervix. Int J Radiat Oncol 2000; 48: 201-211.

13. Sorbe BG, Smeds AC. Postoperative vaginal irradiation with high dose rate afterloading technique in endometrial carcinoma stage I. Int J Radiat Oncol 1990; 18: 305-314.

14. Guy CL, Fields EC, Quinn BA et al. The vaginal cylinder: Misunderstood, misused, or trivial? An in-depth dosimetric and multiinstitutional outcome investigation. Brachytherapy 2019; 18: 763-770.

15. Bahng AY, Dagan A, Bruner DW et al. Determination of prognostic factors for vaginal mucosal toxicity associated with intravaginal high-dose rate brachytherapy in patients with endometrial cancer. Int J Radiat Oncol Biol Phys 2012; 82: 667-673.

16. Aguilera MDV, Rovirosa A, Ascaso C et al. Late G2 vagina toxicity in post-operative endometrial carcinoma is associated with a 68 Gy dose equivalent to 2 Gy per fraction $((\alpha / \beta=$ $3 \mathrm{~Gy})$ ) at $2 \mathrm{~cm}(3)$ of vagina. J Contemp Brachytherapy 2018; 10: 40-46.

17. Kloetzer KH, Günther R, Wendt T. The vaginal stump recurrence rate in endometrial carcinoma in relation to the target volume of postoperative HDR-afterloading brachytherapy. Strahlenther Onkol 1997; 173: 13-17.

18. Choo JJ, Scudiere J, Bitterman P et al. Vaginal lymphatic channel location and its implication for intracavitary brachytherapy radiation treatment. Brachytherapy 2005; 4: 236-240.

19. Townamchai K, Lee L, Viswanathan AN. A novel low dose fractionation regimen for adjuvant vaginal brachytherapy in early stage endometrioid endometrial cancer. Gynecol Oncol 2012; 127: 351-355.

20. Ma DJ, Michaletz-Lorenz M, Goddu SM et al. Magnitude of interfractional vaginal cuff movement: implications for external irradiation. Int J Radiat Oncol Biol Phys 2012; 82: 1439-1444

21. Jhingran A, Salehpour M, Sam M et al. Vaginal motion and bladder and rectal volumes during pelvic intensity-modulated radiation therapy after hysterectomy. Int J Radiat Oncol Biol Phys 2012; 82: 256-262.

22. Ozdemir Y, Dolek Y, Onal C. Effects of vaginal cylinder position on dose distribution in patients with endometrial carcinoma in treatment of vaginal cuff brachytherapy. J Contemp Brachytherapy 2017; 9: 230-235.

23. Chino JP, Jones E, Berchuck A et al. The influence of radiation modality and lymph node dissection on survival in early-stage endometrial cancer. Int J Radiat Oncol Biol Phys 2012; 82: 1872-1879.

24. Lee CM, Szabo A, Shrieve DC et al. Frequency and effect of adjuvant radiation therapy among women with stage I endometrial adenocarcinoma. JAMA 2006; 295: 389-397.

25. Xiang M, Kidd EA. Survival benefit of radiation in high-risk, early-stage endometrioid carcinoma. J Gynecol Oncol 2020; 31: e39.

26. Hou XR, Yu L, Hu K et al. Outcomes of intermediate-risk to high-risk stage I endometrial cancer: 10-year clinical experiences of using in-house multi-channel applicators in a single center. Chin Med J (Engl.) 2019; 132: 1935-1941.
27. Zhang Y, Ascaso C, Herreros A et al. Postoperative endometrial carcinoma treated with external beam irradiation plus vaginal-cuff brachytherapy. Is there a dose relationship with G2 vaginal complications? Rep Pract Oncol Radiother 2020; 25: 227-232.

28. Rovirosa A, Herreros A, Camacho $C$ et al. Comparative results of three short brachytherapy schedules as exclusive treatment in postoperative endometrial carcinoma. Brachytherapy 2017; 16: 1169-1174.

29. Sorbe B, Horvath G, Andersson H et al. External pelvic and vaginal irradiation versus vaginal irradiation alone as postoperative therapy in medium-risk endometrial carcinoma a prospective randomized study. Int J Radiat Oncol Biol Phys 2012; 82: 1249-1255.

30. Diavolitsis V, Rademaker A, Lurain J et al. Clinical outcomes in International Federation of Gynecology and Obstetrics stage IA endometrial cancer with myometrial invasion treated with or without postoperative vaginal brachytherapy. Int J Radiat Oncol Biol Phys 2012; 84: 415-419.

31. Alektiar KM, Venkatraman E, Chi DS et al. Intravaginal brachytherapy alone for intermediate-risk endometrial cancer. Int I Radiat Oncol 2005; 62: 111-117.

32. Horowitz NS, Peters WA 3rd, Smith MR et al. Adjuvant high dose rate vaginal brachytherapy as treatment of stage I and II endometrial carcinoma. Obstet Gynecol 2002; 99: 235-240.

33. Petereit DG, Tannehill SP, Grosen EA et al. Outpatient vaginal cuff brachytherapy for endometrial cancer. Int J Gynecol Cancer 1999; 9: 456-462.

34. Eltabbakh GH, Piver MS, Hempling RE et al. Excellent longterm survival and absence of vaginal recurrences in 332 patients with low-risk stage I endometrial adenocarcinoma treated with hysterectomy and vaginal brachytherapy without formal staging lymph node sampling: report of a prospective trial. Int J Radiat Oncol Biol Phys 1997; 38: 373-380.

35. Park HS, Ratner ES, Lucarelli L et al. Predictors of vaginal stenosis after intravaginal high-dose-rate brachytherapy for endometrial carcinoma. Brachytherapy 2015; 14: 464-470.

36. Law E, Kelvin JF, Thom B et al. Prospective study of vaginal dilator use adherence and efficacy following radiotherapy. Radiother Oncol 2015; 116: 149-155.

37. Son $\mathrm{CH}$, Law E, Oh JH et al. Dosimetric predictors of radiation-induced vaginal stenosis after pelvic radiation therapy for rectal and anal cancer. Int J Radiat Oncol Biol Phys 2015; 92: 548-554.

38. Miles T, Johnson N. Vaginal dilator therapy for women receiving pelvic radiotherapy. Cochrane Database Syst Rev 2014; 2014: CD007291-CD007291.

39. Bruner DW, Nolte SA, Shahin MS et al. Measurement of vaginal length: reliability of the vaginal sound - a Gynecologic Oncology Group Study. Int J Gynecol Cancer 2006; 16: 1749.

40. Bruner DW, Lanciano R, Keegan $M$ et al. Vaginal stenosis and sexual function following intracavitary radiation for the treatment of cervical and endometrial carcinoma. Int J Radiat Oncol 1993; 27: 825-830.

41. Rubin P, Constine LS, Fajardo LF et al. Late effects consensus conference: RTOG/EORTC. Radiother Oncol 1995; 35: 5-7.

42. LENT SOMA scales for all anatomic sites. Int J Radiat Oncol Biol Phys 1995; 31: 1049-1091. 